\title{
El nuevo régimen de las medidas cautelares contempladas en la Ley 1437 de 2011 y su aplicación en la jurisdicción contenciosa administrativa
}

\author{
Yezid García-Saenz \\ Lina Beatriz Gómez-Durán ${ }^{* *}$ \\ Elizabeth Puentes-Peña ${ }^{* * *}$
}

* Doctor en Derecho y Ciencias Políticas, Universidad Santo Tomás, Bogotá. Docente de Derecho Procesal Administrativo, Universidad Cooperativa de Colombia, Bucaramanga, Colombia. Correo electrónico: ygarcias@procuraduria.gov.co

** Estudiante de Derecho, Universidad Cooperativa de Colombia, Bucaramanga, Colombia. Correo electrónico: ligo19@hotmail.com

*** Estudiante de Derecho, Universidad Cooperativa de Colombia, Bucaramanga, Colombia. Correo electrónico: elizabethpuentes19@hotmail.com

Recibido: 5 de octubre 2014 Aprobado: 31 de octubre 2014

Cómo citar este artículo: Yesid García-Saenz, Lina Beatriz GómezDurán y Elizabeth Puentes-Peña. El nuevo régimen de las medidas cautelares contempladas en la Ley 1437 de 2011 y su aplicación en la jurisdicción contenciosa administrativa. DIXI 20. Diciembre 2014. Pág. 37. doi: http://dx.doi.org/10.16925/ di.v16i20.833

\section{Resumen}

Las medidas cautelares son instrumentos por medio de los cuales el ordenamiento jurídico busca proteger derechos que están siendo controvertidos dentro de un proceso. Es por esto que con la expedición de la Ley 1437 de 2011 se buscó fortalecer los poderes del juez a fin de lograr esta protección, ya que dentro de la jurisdicción contenciosa administrativa la única cautela posible era la suspensión provisional de los efectos del acto administrativo. Esto, además de resultar insuficiente, era de difícil aplicación por la rigurosidad de sus requisitos. Razón por la cual la citada norma no sólo incluye nuevas medidas cautelares, sino que también flexibilizó los requerimientos de la existente a fin de hacer más fácil su aplicación. Dada la novedad en el manejo de las medidas cautelares en la jurisdicción contenciosa administrativa, y en conformidad con la nueva norma procesal administrativa que entró en vigencia el 2 de julio de 2012, es necesario realizar precisiones sobre su funcionamiento, su procedencia en los diferentes medios de control y su real aplicación, con el fin de determinar si estas brindan garantías de un adecuado cumplimiento del fallo.

Palabras clave: medidas cautelares, medios de control, Ley 1437 de 2011, suspensión provisional.

The New System of Precautionary Measures Contemplated in Law 1437 of 2011 AND its Application in the Contentious Administrative Jurisdiction

Abstract

Precautionary measures are instruments used by the legal order to protect rights that are being violated within a proceeding. The aim of Law 1437 of 2011 was therefore to strengthen the powers of judges in order to achieve this protection, insofar as in the contentious administrative jurisdiction, the only possible measure had been to provisionally suspend the effects of an administrative act. This was not only insufficient but difficult to apply because of the rigor of its requirements. That was why the above-mentioned norm not only included new precautionary measures but also made the existing requirements more flexible to facilitate their application. Because precautionary measures in the contentious administrative jurisdiction are a new phenomenon, and in accordance with the new administrative procedural norm that became effective on July 2, 2012, there is a need for clarification about its functioning, applicability in the diverse control measures and real application, in order to determine whether it provides guarantees of adequate fulfillment of rulings.

Keywords: precautionary measures, control measures, Law 1437 of 2011, provisional suspension.

O NOVO REGIME DAS MEDIDAS CAUTELARES PREVISTAS PELA LEI 1437 DE 2011 E SUA APLICAÇÃo NA JURISDIÇÃo CONTENCIOSA ADMINISTRATIVA

\section{Resumo}

As medidas cautelares são instrumentos através dos quais o ordenamento jurídico procura proteger direitos que estão sendo controvertidos dentro de um processo. É por isso que com a emissão da Lei 1437 de 2011 se tentou fortalecer os poderes do juiz com o intuito de conseguir essa proteção, já que dentro da jurisdição contenciosa administrativa a única cautela possível era a suspensão temporária dos efeitos do ato administrativo. Isto, além de ser insuficiente, era de difícil aplicação pela rigorosidade de seus requisitos. Por isso, a referida norma não somente inclui novas medidas cautelares, mas também flexibilizou os requerimentos da norma existente visando facilitar sua aplicação. Pela novidade no manejo das medidas cautelares na jurisdição contenciosa administrativa, e conforme a nova norma processual administrativa que começou a vigorar no dia 2 de julho de 2012, é necessário fazer precisões em relação ao seu funcionamento, sua procedência nos diversos meios de controle e sua aplicação rela, com o intuito de determinar se elas oferecem garantias de um adequado cumprimento da sentença.

Palavras-chave: medidas cautelares, meios de controle, Lei 1437 de 2011, suspensão temporária. 


\section{INTRODUCCIÓN}

El presente artículo parte de una investigación realizada en relación con las nuevas medidas cautelares consagradas en la Ley 1437 de 2011, teniendo en cuenta que hasta la entrada en vigencia de la norma en comento, esto es, el 2 de julio de 2012, la única cautela aplicable era la suspensión provisional de los efectos de los actos administrativos. Esta medida sólo era procedente en algunos medios de control tales como la nulidad, nulidad y restablecimiento del derecho, controversias contractuales y nulidad electoral, modificados todos con la nueva norma. Todo esto hizo necesario realizar precisiones sobre su apropiada utilización, procedencia, recursos disponibles, oportunidad para solicitarlas, requisitos para su decreto, cuándo es requerida la caución, medidas cautelares de urgencia, levantamiento, modificación y revocatoria, así como las sanciones y la responsabilidad por su decreto sin el cumplimiento de requisitos. Igualmente, se hizo necesario realizar un estudio sobre la procedencia de las medidas cautelares en los diferentes medios de control y su real aplicación en la jurisdicción contenciosa administrativa.

Todo lo anterior, con el fin de determinar si las medidas cautelares contempladas en la Ley 1437 de 2011 dan garantías de un efectivo cumplimiento del fallo en los procesos declarativos adelantados ante la Jurisdicción Contenciosa Administrativa.

\section{Procedimiento PARA LA}

\section{SOLICITUD Y DECRETO DE LAS MEDIDAS CAUTELARES CONSAGRADAS EN LA LEY}

\section{DE 2011}

Las medidas cautelares han sido definidas por la Corte Constitucional como

aquellos instrumentos con los cuales el ordenamiento protege, de manera provisional, y mientras dura el proceso, la integridad de un derecho que es controvertido en ese mismo proceso. De esa manera el ordenamiento protege preventivamente a quien acude a las autoridades judiciales a reclamar un derecho, con el fin de garantizar que la decisión adoptada sea materialmente ejecutada. ${ }^{1}$

1. Corte Constitucional de Colombia. Sentencia C-490 De 2000. (M. P. Alejandro Martínez Caballero; mayo 4 de 2000).
Sin embargo, en la Jurisdicción Contenciosa Administrativa la única medida cautelar aplicable era la suspensión provisional de los efectos de los actos administrativos, restringiendo al juez los instrumentos para lograr una tutela judicial efectiva. Precisamente esta restricción fue uno de los motivos que condujo al legislador al fortalecimiento de los poderes judiciales con la expedición de la Ley 1437 de 2011, a través de la inclusión de nuevas medidas cautelares.

Esta norma establece que el juez puede decretar las medidas cautelares que considere necesarias para proteger de manera provisional el objeto del proceso y la efectividad de la sentencia. Específicamente, el artículo 230 clasifica las medidas cautelares como preventivas (pretenden evitar la configuración de un perjuicio al solicitante de la medida), anticipativas (con ellas se adelantan los efectos de la sentencia), conservativas (buscan mantener la situación anterior al conflicto mientras se toma una decisión definitiva en la sentencia), y de suspensión (consistentes en la suspensión de los actos administrativos y de actuaciones administrativas). Igualmente, ofrece un listado de medidas que el juez puede decretar:

1. Ordenar que se mantenga la situación, o que se restablezca al estado en que se encontraba antes de la conducta vulnerante o amenazante, cuando fuere posible.

2. Suspender un procedimiento o actuación administrativa, incluso de carácter contractual. A esta medida sólo acudirá el Juez o Magistrado Ponente cuando no exista otra posibilidad de conjurar o superar la situación que dé lugar a su adopción y, en todo caso, en cuanto ello fuere posible el Juez o Magistrado Ponente indicará las condiciones o señalará las pautas que deba observar la parte demandada para que pueda reanudar el procedimiento o actuación sobre la cual recaiga la medida.

3. Suspender provisionalmente los efectos de un acto administrativo.

4. Ordenar la adopción de una decisión administrativa, o la realización o demolición de una obra, con el objeto de evitar o prevenir un perjuicio o la agravación de sus efectos.

5. Impartir órdenes o imponerle a cualquiera de las partes del proceso obligaciones de hacer o no hacer. 
En relación con el procedimiento para la solicitud y decreto de las medidas cautelares consagradas en el Código de Procedimiento Administrativo y de lo Contencioso Administrativo, lo primero a destacar es su procedencia en todos los procesos declarativos adelantados ante la Jurisdicción Contenciosa Administrativa, y ya no sólo en algunos medios de control como en la nulidad, nulidad y restablecimiento del derecho, controversias contractuales y nulidad electoral. Igualmente, cabe resaltar que la medida cautelar puede ser solicitada desde la presentación de la demanda, hasta antes de ser notificado el auto admisorio o en cualquier estado del proceso. A diferencia de la normatividad anterior que sólo permitía solicitar la suspensión provisional hasta antes de ser proferido el auto admisorio de la demanda.

Respecto a los requisitos para decretar una medida cautelar consagrados en el artículo 231 de la Ley 1437 de 2011, se puede apreciar una distinción en tratándose de la suspensión provisional de un acto administrativo, pues en este caso establece:

(Cuando se pretenda la nulidad de un acto administrativo, la suspensión provisional de sus efectos procederá por violación de las disposiciones invocadas en la demanda o en la solicitud que se realice en escrito separado, cuando tal violación surja del análisis del acto demandado y su confrontación con las normas superiores invocadas como violadas o del estudio de las pruebas allegadas con la solicitud. Cuando adicionalmente se pretenda el restablecimiento del derecho y la indemnización de perjuicios deberá probarse al menos sumariamente la existencia de los mismos.) $)^{2}$

Situación que difiere de la anterior norma en la que se establecía que la violación de la disposición debía evidenciarse de manera manifiesta, clara, ostensible, por simple confrontación, ya que de requerir un análisis profundo la suspensión provisional no era procedente, y era una de las razones por las cuales esta medida era decretada sólo ocasionalmente.

Para las demás medidas cautelares, se pueden identificar tres requisitos esenciales: la apariencia de buen derecho, el peligro en la demora y la ponderación de intereses en conflicto. El primero se refiere a que quien

2. Ley 1437 de 2011. Por la cual se expide el Código de Procedimiento Administrativo y de lo Contencioso Administrativo. Enero 18 de 2011. Do N. ${ }^{\circ} 47.956$. Art. 231, inciso primero. La cursiva es añadida. solicita la medida cautelar, cuente con los suficientes argumentos de hecho y de derecho para reclamar su pretensión; la apariencia de buen derecho se encuentra consagrada en los numerales 1 y 2 del artículo 231 de la Ley 1437 de 2011. ${ }^{3}$ El peligro en la demora consiste en hacerle ver al juez que debido a la duración del proceso puede no lograrse una tutela judicial efectiva si no se decreta la medida cautelar, requisito que puede identificarse en el numeral 4 del mismo artículo. ${ }^{4}$ Finalizando con la ponderación de intereses en conflicto, este requisito surge cuando la norma exige: "Que el demandante haya presentado los documentos, informaciones, argumentos y justificaciones que permitan concluir, mediante un juicio de ponderación de intereses, que resultaría más gravoso para el interés público negar la medida cautelar que concederla." En este punto, el juez debe identificar los intereses en conflicto, valorarlos y decidir cuál debe prevalecer, prestando especial atención, debido al alto componente subjetivo que comporta este punto; igualmente, debe recordar que el decreto de una medida cautelar no implica prejuzgamiento.

Otro punto importante es el relativo a la caución, requisito indispensable para garantizar los posibles perjuicios que se puedan ocasionar a la contraparte y que debe prestarse para la ejecución de la medida cautelar, en cuantía y modalidad decidida por el juez. Sin embargo, en todos los casos no se requiere, ya que la norma expresamente lo dispone en tratándose de la suspensión provisional de los efectos de los actos administrativos, en los procesos relativos a la defensa y protección de los derechos e intereses colectivos, en los procesos de tutela y cuando el solicitante sea una entidad pública.

En cuanto al procedimiento para decretar una medida cautelar, ya sea la suspensión provisional o cualquier otra, resalta el hecho del deber de correrle traslado de la solicitud a la parte que se verá afectada con la medida para que se pronuncie sobre esta. Trámite que varía según el momento de solicitar la medida cautelar, porque si esto ocurre al momento de presentar la demanda o antes de notificar el auto admisorio, el

\footnotetext{
3. Numeral 1: Que la demanda esté razonablemente fundada en derecho. Numeral 2: Que el demandante haya demostrado, así fuere sumariamente, la titularidad del derecho o de los derechos invocados.

4. Que, adicionalmente, se cumpla una de las siguientes condiciones: a) Que al no otorgarse la medida se cause un perjuicio irremediable, o b) Que existan serios motivos para considerar que de no otorgarse la medida los efectos de la sentencia serían nugatorios.

5. Ley 1437 de 2011, supra, nota 2. Art. 23, numeral 3.
} 
juez ordenará correr traslado en auto separado por el término de cinco (5) días junto con la notificación del auto admisorio. No obstante, si la medida es solicitada en cualquier estado del proceso, el traslado es de tres (3) días, en la forma establecida por el artículo 110 del Código General del Proceso. Tratándose de medidas solicitadas en audiencia, el traslado ocurre durante la misma diligencia. Sin embargo, el traslado puede omitirse en caso de las medidas cautelares de urgencia, siempre y cuando se cumplan con los requisitos exigidos para su decreto.

En cuanto a los recursos, tratándose de medidas cautelares, la norma establece que son procedentes los de apelación y de súplica contra el auto que decreta una medida cautelar. El de apelación en procesos de primera instancia y el de súplica en procesos de única o segunda instancia. Sin embargo, guarda silencio en el evento de negarse la medida cautelar, por lo cual es necesario remitirse al artículo 242 de la Ley 1437 de 2011, según el cual procede el recurso de reposición contra autos no susceptibles del recurso de apelación o súplica, como en este caso.

Cabe resaltar que aunque una medida cautelar sea decretada, esta puede ser también levantada, modificada o revocada. Según lo dispone el artículo 235 de la Ley 1437 de 2011, para levantar una medida el afectado debe prestar caución a satisfacción del juez, a fin de garantizar los perjuicios que se lleguen a causar. En los casos de modificación o revocatoria, proceden a solicitud de parte o de oficio cuando se advierta que no se cumplieron los requisitos para su decreto o que las razones que le dieron origen ya se superaron. En estos dos eventos no se requiere caución y frente a la decisión adoptada no proceden recursos.

Por último, establece esta ley que en el evento de revocarse una medida cautelar en el transcurso del proceso por improcedente o por sentencia desestimatoria, quien la haya solicitado debe responder por los perjuicios causados, por medio de incidente que debe ser promovido dentro de los treinta (30) días siguientes a la ejecutoria de la providencia, salvo que se trate de la suspensión provisional de un acto administrativo de carácter general.

Frente al incumplimiento de una medida cautelar, la norma contempla multas sucesivas por cada día de retardo, las cuales pueden llegar hasta el monto de dos salarios mínimos legales mensuales vigentes, sin sobrepasar los cincuenta salarios a cargo del renuente.

\section{Procedencia de las MEdidAS CAUTELARES EN LOS DIFERENTES MEDIOS DE CONTROL ADELANTADOS EN LA JURISDICCIÓN CONTENCIOSA ADMINISTRATIVA}

$\mathrm{Al}$ analizar las medidas cautelares en los diferentes medios de control adelantados ante la jurisdicción contenciosa administrativa, se pueden diferenciar tres grupos. El primero, constituido por aquellos medios de control cuyo procedimiento para el decreto de las medidas cautelares es el consagrado en la Ley 1437 de 2011. En el segundo grupo, se encuentran aquellos medios de control con un trámite especial en materia de procedimiento y cautelas. Por último, aquellos medios de control en los cuales no se consideran procedentes las medidas cautelares.

En el primer grupo encontramos: la nulidad, nulidad y restablecimiento del derecho, reparación directa y controversias contractuales, medios de control en los que al momento de solicitar y decretar una medida cautelar, se aplica el procedimiento consagrado en la Ley 1437 de 2011, en sus artículos 229 a 241, explicado previamente.

El segundo grupo consta de la nulidad por inconstitucionalidad, la nulidad electoral, repetición, protección de los derechos e intereses colectivos, reparación de los perjuicios causados a un grupo y la acción de tutela. Tratándose de la nulidad por inconstitucionalidad, el trámite es el consagrado en el artículo 184 del Código de Procedimiento Administrativo y de lo Contencioso Administrativo, y sólo es procedente la suspensión provisional. Algo similar ocurre con la nulidad electoral, cuyo procedimiento es el establecido en los artículos 275 y siguientes de la norma en comento, e igualmente sólo es admisible la suspensión provisional. Para la repetición se mantiene lo regulado en la Ley 678 de 2001, en la cual son procedentes las medidas de embargo y secuestro de bienes y la inscripción de la demanda de bienes sujetos a registro. Igualmente, son admisibles para este proceso las medidas cautelares consagradas en la Ley 1437 de 2011. En el caso de los procesos cuya finalidad es la protección de los derechos e intereses colectivos y la reparación de los perjuicios causados a un grupo, estos se siguen tramitando por la Ley 472 de 1998, pero con la salvedad de que, tratándose de los primeros, las medidas cautelares se deben tramitar según lo establecido en la Ley 1437 de 2011, tal como lo dispone el parágrafo del artículo 229 de esta ley: 
PARÁGRAFO. Las medidas cautelares en los procesos que tengan por finalidad la defensa y protección de los derechos e intereses colectivos y en los procesos de tutela del conocimiento de la Jurisdicción de lo Contencioso Administrativo se regirán por lo dispuesto en este capítulo y podrán ser decretadas de oficio

En lo referente a la acción de tutela, es importante destacar que a pesar de que en el Código de Procedimiento Administrativo y de lo Contencioso Administrativo se establece que las medidas cautelares tramitadas en los procesos de tutela adelantados ante la jurisdicción de lo contencioso administrativo se regirán por lo dispuesto en el código en comento, la Corte Constitucional mediante sentencia C-284 de 2014 declaró inexequible la expresión " $y$ en los procesos de tutela", ya que los términos que se manejan en la Ley 1437 de 2011 no resultan aplicables, dado el trámite expedito que tiene la tutela, además que se vulneraría el derecho a la igualdad de los sujetos procesales al aplicarse un régimen diferenciado para la jurisdicción contenciosa administrativa. En consecuencia, las acciones de tutela seguirán tramitándose en todas las jurisdicciones según lo establecido en el Decreto 2591 de 1991.

Finalmente, no se consideran procedentes las medidas cautelares en los medios de control inmediato de legalidad, de pérdida de investidura, en el cumplimiento de normas con fuerza material de ley o de actos administrativos, en la nulidad de cartas de naturaleza y resoluciones de autorización de inscripción, así como en el control por vía de excepción.

Respecto al control inmediato de legalidad, no procede por tratarse de un trámite oficioso y no un proceso contencioso en el cual se pueda hablar de partes en el proceso. En cuanto a la pérdida de investidura y la pretensión de cumplimiento de normas con fuerza material de ley o de actos administrativos, estos cuentan con norma especial, y su trámite se encuentra contenido en la Ley 144 de 1994 y en la Ley 393 de 1997, respectivamente, en las que no se contemplan medidas cautelares dado lo expedito del proceso.

En el caso de la nulidad de cartas de naturaleza y resoluciones de autorización de inscripción, el parágrafo primero del artículo 20 de la Ley 43 de 1993, expresamente establece que no procede la suspensión provisional, pues ninguna persona puede verse privada de la nacionalidad, si no es por sentencia de fondo, es

6. Véase Corte Constitucional de Colombia. Sentencia C-284 DE 2014. (M. P. María Victoria Calle Correa; mayo 15 de 2014). decir, cuando se encuentren debidamente probadas las causales por las cuales se puede invocar este medio de control. Y para el control por vía de excepción, basta decir que no es un proceso como tal, sino una excepción dentro de un proceso, en la cual el juez inaplica un acto administrativo, ya sea de oficio o a petición de parte, por considerar que vulnera la Constitución y la ley (cabe recordar que esta decisión sólo tiene efectos interpartes).

\section{ApliCACIÓN DE LAS MEDIDAS CAUTELARES EN LA JURISDICCIÓN CONTENCIOSA ADMINISTRATIVA}

Para observar la aplicación de las nuevas medidas cautelares consagradas en la Ley 1437 de 2011, es posible tomar como ejemplo el proceso de nulidad y restablecimiento del derecho adelantado por el Alcalde Mayor de Bogotá, Gustavo Francisco Petro Urrego, interpuesta con el fin de que se declare la nulidad del acto administrativo sancionatorio emitido por la Sala Disciplinaria de la Procuraduría General de la Nación, de fecha 9 de diciembre de 2013 y su ratificación el 13 de enero de 2014, mediante los cuales se le destituyó de su cargo e inhabilitó para ejercer cargos públicos por el término de quince años.

Dentro del mencionado proceso presentado ante el Consejo de Estado el 31 de marzo de 2014, se solicitó como medida cautelar en calidad de urgencia, la suspensión provisional de los actos administrativos demandados. Por lo cual, el Consejero Ponente, Dr. Gerardo Arenas Monsalve, el 10 de marzo del mismo año profirió auto admisorio de la demanda, ordenando en el mismo auto correrle traslado a la parte demandada del escrito demandatorio y de la solicitud de la medida cautelar, sin dar el trámite de urgencia por considerar que lo que se debate es un acto administrativo sancionatorio, que tuvo un proceso previo complejo y que adicionalmente no se puede decretar una medida cautelar sólo con los argumentos de la parte demandante. Asimismo, teniendo en cuenta que el traslado es sólo de cinco (5) días, no se consideró que se afectara significativamente la urgencia de la medida.

A su debido término, la Procuraduría presentó escrito de oposición a la medida cautelar y así, al contar con la sustentación de las partes, a favor y en contra, el Consejo de Estado procedió a analizar los respectivos 
argumentos con el fin de determinar la procedencia de la medida solicitada por el demandante, la cual fue decretada mediante auto de fecha 13 de mayo de 2014, siguiendo así el procedimiento establecido en la Ley 1437 de 2011.

\section{Conclusiones}

Uno de los aspectos novedosos e importantes de la Ley 1437 de 2011, fue la regulación de las medidas cautelares que se pueden solicitar y decretar dentro del proceso contencioso administrativo.

Las medidas cautelares no habían sido objeto de un estudio riguroso y expreso como el que han tenido con la expedición del Código de Procedimiento Administrativo y de lo Contencioso Administrativo, a excepción de la suspensión provisional de los efectos de los actos administrativos, única medida cautelar existente ("reina"), hasta antes de la reforma del procedimiento administrativo.

Las medidas cautelares pueden ser decretadas por el Juez o Magistrado Ponente, en todos los procesos declarativos que se adelanten ante su Jurisdicción, en pro-videncia motivada con el fin de proteger y garantizar provisionalmente el objeto del proceso y la efectividad de la sentencia. Así mismo, estas medidas pueden intentarse en cualquier etapa del proceso, con lo cual se rompe la vieja tradición existente en derecho procesal, según la cual debía formularse antes de que trabe la litis.

Se hizo una clasificación de medidas cautelares, como la señalada el artículo 230 del CPACA, en que se establece que pueden ser preventivas, conservativas, anticipativas o de suspensión y se pueden formular en cualquier estado del proceso, con el lleno de unos requisitos, dependiendo de si se trata de demandas en las que se pretende la nulidad de los actos administrativos o de las que se promueven en ejercicio de los demás medios de control.

La existencia de una amplia gama de requisitos para decretarlas se debe a la obligación y deber de la Jurisdicción Contencioso Administrativo de ejercer el control judicial de la administración pública.

Otro punto importante a resaltar es que las medidas cautelares no implican prejuzgamiento, en razón a su naturaleza eminentemente temporal, elemento homogéneo en todas las legislaciones que las contemplan.
Por otra parte, el artículo 229 del CPACA reitera que las medidas cautelares no proceden de oficio sino a petición de parte, a diferencia de las que se admiten en el medio de control de protección de los derechos e intereses colectivos y de tutela.

Si concurren los requisitos para que se garantice de manera sustancial la efectividad de un derecho a obtener un eficaz amparo cautelar, cuando se acrediten aquellos, el juez puede adoptar las medidas que considere necesarias para garantizar provisionalmente el objeto del proceso y la seguridad de la sentencia.

Además, la ley exige caución por parte de quien solicite una medida cautelar, con el fin de garantizar los perjuicios que se puedan ocasionar con esta. El Juez o Magistrado debe de determinar la modalidad, cuantía y demás condiciones de la caución.

De igual manera, nuestra legislación estableció un procedimiento novedoso para la adopción de las medidas cautelares, como lo es el traslado de la solicitud de la medida para que el demandado se pronuncie al respecto, de forma previa a la decisión del juez. Se crearon, además, las Medidas Cautelares de Urgencia pretermitiendo los trámites correspondientes, esto es, la notificación a la otra parte, como lo dispone el artículo 234 del CPACA. Solamente se exige el cumplimiento de los demás requisitos para su adopción.

De la misma forma en que se puede decretar una medida cautelar, se puede levantar a solicitud del demandado o del afectado, prestando la caución correspondiente señalada por el juez, en orden a garantizar la reparación del daño y perjuicio que pueda causar. Asimismo, la medida decretada puede ser modificada o revocada de oficio o a petición de parte. En estos casos las decisiones relacionadas con el levantamiento, la modificación o revocatoria de la medida cautelar no son susceptibles de recurso alguno.

Es de precisar que, en la regulación de las medidas cautelares (Ley 1437 de 2011), se establecieron las garantías legales que ofrece el Estado a través de la ley en orden a la protección de los derechos de las partes en un proceso, como lo son los recursos contemplados en el artículo 236 de la mencionada norma.

Todo lo relativo a las medidas cautelares propuesto en el CPACA requiere de un cambio procesal en los sujetos procesales, quienes deben estar atentos a la carga probatoria exigida, y a los Jueces, quienes deben tomar conciencia de las nuevas herramientas (poderes) que la ley les otorgó para que puedan crear decisiones en derecho. 


\section{REFERENCIAS}

Corte Constitucional de Colombia. Sentencia C-490 DE 200o. (M. P. Alejandro Martínez Caballero; mayo 4 de 2000).

Corte Constitucional de Colombia. Sentencia C-284 De 2014. (M. P. María Victoria Calle Correa; mayo 15 de 2014).

Decreto 2591 de 1991. Por el cual se reglamenta la acción de tutela consagrada en el artículo 86 de la Constitución Política. Noviembre 19 de 1991.

Ley 43 de 1993. Por medio de la cual se establecen las normas relativas a la adquisición, renuncia, pérdida y recuperación de la nacionalidad colombiana; se desarrolla el numeral 7 del artículo 40 de la Constitución Política y se dictan otras disposiciones. Febrero 1 de 1993. DO N. ${ }^{\circ} 40.735$.
Ley 144 de 1994. Por la cual se establece el procedimiento de pérdida de la investidura de los congresistas. Julio 19 de 1994. Do N. ${ }^{\circ} 41.449$.

Ley 393 de 1997. Por la cual se desarrolla el artículo 87 de la Constitución Política. Julio 30 de 1997. Do N. 43096.

Ley 472 de 1998. Por la cual se desarrolla el artículo 88 de la Constitución Política de Colombia en relación con el ejercicio de las acciones populares y de grupo y se dictan otras disposiciones. Agosto 5 de 1998. Do N. ${ }^{\circ} 43.357$.

Ley 678 de 2001. Por medio de la cual se reglamenta la determinación de responsabilidad patrimonial de los agentes del Estado a través del ejercicio de la acción de repetición o de llamamiento en garantía con fines de repetición. Agosto 4 de 2001. Do N. ${ }^{\circ} 44509$.

Ley 1437 de 2011. Por la cual se expide el Código de Procedimiento Administrativo y de lo Contencioso Administrativo. Enero 18 de 2011. Do N. ${ }^{\circ} 47.956$. 